\title{
Effects of a Rehabilitation Nursing Program on the Functional Fitness of Institutionalized Elderly
}

\author{
Efeitos de um Programa de Enfermagem de Reabilitação na Aptidão Funcional de Idosos \\ Institucionalizados \\ Efectos de un Programa de Enfermería de Rehabilitación en la Aptitud Funcional de \\ Ancianos Institucionalizados
}

Leonel São Romão Preto*; Joana Rita Lamas Gomes**; André Filipe Morais Pinto Novo***;

Maria Eugénia Rodrigues Mendes****; José Granero-Molina*****

\begin{abstract}
Background: Functional fitness is essential for the autonomous performance of activities of daily living. The functional fitness of the elderly includes several components: strength, aerobic training, flexibility, balance, and body composition.

Objectives: To assess changes in the functional fitness of institutionalized elderly based on a Rehabilitation Nursing Program using moderate-intensity physical activity.

Methodology: Pre-test/post-test design with control group. The intervention program included three 30-minute sessions per week, for a period of 6 months. Functional fitness was assessed using the Functional Fitness Test (FFT) battery for older adults. Fifteen participants were assigned to the intervention group (IG), and ten participants to the control group (CG).

Results: A significant increase $(\mathrm{p}<0.05)$ of grip strength, arm curl strength, mobility, agility/dynamic balance, and one-leg balance was observed in the IG $(85.9 \pm 6.1$ years $)$. The CG $(85.8 \pm 4.6$ years $)$ showed no significant changes in any of the functional fitness components.

Conclusion: The results suggest an improvement of the functional fitness of the elderly in the IG.
\end{abstract}

Keywords: outcome assessment (health care); rehabilitation; physical fitness; aged

\section{Resumo}

Enquadramento: A aptidão funcional é essencial à execução autónoma das atividades de vida diária. A aptidão funcional em idosos inclui vários componentes: força; treino aeróbico; flexibilidade; equilíbrio e composição corporal.

Objetivos: Avaliar mudanças na aptidão funcional de idosos institucionalizados através de um programa de enfermagem de reabilitacão baseado em exercício físico de moderada intensidade.

Metodologia: Desenho pré-teste/pós-teste com grupo de controlo. O programa de intervenção incluiu 3 sessões semanais de 30 minutos cada, durante 6 meses. A aptidão funcional foi avaliada pela bateria de testes Functional Fitness Test (FFT) para idosos. O grupo de intervenção (GI) tinha 15 participantes e o grupo de controlo (GC) 10.

Resultados: No GI (85,9 \pm 6,1 anos) observámos um aumento significativo $(p<0,05)$ da força de preensão manual; força de flexão do braço; mobilidade, agilidade/equilíbrio dinâmico e do equilíbrio unipodal. No GC (85,8 \pm 4,6 anos) não se registaram alterações significativas em qualquer das componentes da aptidão funcional. Conclusão: Os resultados sugerem que os idosos do GI melhoraram a sua aptidão funcional.

Palavras-chave: avaliação de resultados (cuidados de saúde); reabilitação; aptidão física; idoso

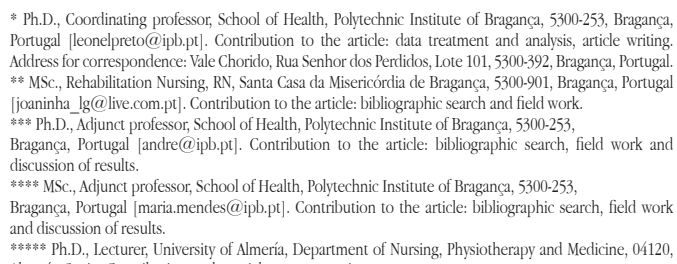

* Ph.D., Coordinating professor, School of Health, Polytechnic Institute of Bragança, 5300-253, Bragança, Portugal [leonelpreto@ipb.pt]. Contribution to the article: data treatment and analysis, article writing Address for correspondence: Vale Chorido, Rua Senhor dos Perdidos, Lote 101, 5300-392, Bragança, Portugal. ** MSc., Rehabilitation Nursing, RN, Santa Casa da Misericórdia de Bragança, 5300-901, Bragança, Portugal [joaninha_lg@live.com.pt]. Contribution to the article: bibliographic search and field work. *** Ph.D., Adjunct professor, School of Health, Polytechnic Institute of Bragança, $5300-253$, discussion of results.

***** MSc., Adjunct professor, School of Health, Polytechnic Institute of Bragança, 5300-253. Bragança, Portugal [maria.mendes@ipb.pt]. Contribution to the article: bibliographic search, field work and discussion of results.

****** Ph.D., Lecturer, University of Almería, Department of Nursing, Physiotherapy and Medicine, 04120, Almería, Spain. Contribution to the article: content review.

\section{Resumen}

Marco contextual: La aptitud funcional es fundamental para ejecutar con autonomía las actividades de la vida diaria. La aptitud funcional en ancianos incluye varios componentes: fuerza, entrenamiento aeróbico, flexibilidad, equilibrio y composición corporal.

Objetivos: Evaluar los cambios en la aptitud funcional de ancianos institucionalizados mediante un programa de enfermería de rehabilitación basado en el ejercicio físico de intensidad moderada.

Metodología: Diseño pretest/postest con un grupo de control. El programa de intervención incluyó tres sesiones semanales de 30 minutos cada una durante 6 meses. La aptitud funcional se evaluó mediante la batería de pruebas FFT (Functional Fitness Test) para ancianos. El grupo de intervención (GI) tenía 15 participantes y el grupo de control (GC) 10.

Resultados: En el GI (85,9 \pm 6,1 años) se observó un aumento significativo $(p<0,05)$ de la fuerza de prensión manual, fuerza de flexión del brazo, movilidad, agilidad/equilibrio dinámico y equilibrio unipodal. En el GC (85,8 \pm 4,6 años) no hubo cambios significativos en los componentes de la aptitud funcional.

Conclusión: Los resultados sugieren que los ancianos del GI mejoraron su aptitud funcional.

Palabras clave: evaluación de resultado (atención de salud); rehabilitación; aptitud física; anciano

Received for publication: 30.03 .15

Accepted for publication: 04.11 .15 


\section{Introduction}

The progressive aging of the Portuguese population is a sociodemographic reality well-documented in several studies (Carneiro, Soares, Fialho, \& Sacadura, 2012). We have been witnessing an increase in life expectancy, together with a significant increase in the aging index and in the old-age dependency ratio. The latter is a relevant health indicator and has grown exponentially in Portugal, reaching one of the highest rates of dependence in the European Union (Carneiro et al., 2012).

The aging process brings about a series of changes in the physiological systems that cause the person to be less efficient in terms of functional capacity, particularly bone and muscle mass decline, and neurological and motor function impairment (Elbaz et al., 2013; Rondanelli et al., 2014). Balance, flexibility, muscle strength, and joint motion decrease very quickly in institutionalized elderly without any physical activity or active aging programs (Preto, Santos, Mendes, Novo, \& Pimentel, 2015).

Several studies have emphasized that maximal oxygen uptake $\left(\mathrm{VO}_{2 \max }\right)$ declines with age and that activities of daily living (ADLs) demand an increasing percentage of $\mathrm{VO}_{2 \max }$ in advancing age, which may contribute to understanding the functional impairment of the elderly (Rydwik, Frändin, \& Akner, 2004).

The main objective of our research was to assess the effectiveness of a Rehabilitation Nursing Program (RNP) using moderate-intensity physical activity on the functional fitness of institutionalized elderly. Our specific goals were to assess the participants, before and after the intervention program, regarding the following variables: grip strength, pinch strength, upper limb global strength, upper body flexibility, trunk flexibility, mobility/global agility and dynamic balance, one-leg balance, and lower limb strength, as well as to compare the results obtained in the different groups (intervention and control).

\section{Background}

The decline in physical abilities with age often represents the early stage of a process which, associated with sedentarism, institutionalization or comorbidities, leads to dependence and other adverse health outcomes (Vieira et al., 2013).
According to Rikli and Jones (2008), functional fitness is the physical ability to perform normal everyday activities safely, independently and without undue fatigue. The concept of physical fitness, or functional fitness, includes multiple perspectives, from sports performance to aspects related to an individual's health, function and quality of life. Among the elderly, health-related functional fitness values components associated with the prevention of diseases and falls or the frailty syndrome, such as cardiorespiratory endurance, muscle strength and endurance, flexibility, and body composition (Caspersen, Powell, $\&$ Christenson, 1985). The role played by the above mentioned variables in the functional independence and quality of life of the elderly is becoming widely accepted (Chou, Hwang, \& Wu, 2012; Vermeulen, Neyens, Rossum, Spreeuwenberg, \& Witte, 2011).

For example, maintaining muscle strength is essential to achieve a secure gait and perform several activities of daily living, such as carrying objects, sitting and standing, climbing stairs. According to Souza, Benedetti, Borges, Mazo, and Gonçalves (2011), muscle strength is the physical ability more closely associated with independence. In addition to muscle strength, other functional fitness variables, such as balance, agility and joint flexibility, have been associated with the functional performance of the elderly. The participation in intervention programs using active and resistance exercises can increase functional performance, and contribute to improve quality of life and fall prevention within this age group (Chou et al., 2012; El-Khoury, Cassou, Charles, \& Dargent-Molina, 2013).

Based on the results from the pre- and postintervention assessments, we will be able to understand the changes occurred within the factors, and plan new training programs. However, according to Chávez-Pantoja, López-Mendoza, and Mayta-Tristán (2014), most institutions have no specific programs for the elderly due to lack of resources, or when they do have such programs, these interventions are designed to keeping them active, rather than improving their physical abilities.

\section{Hypotheses}

We formulated the following hypotheses:

H1 - Grip strength, pinch strength, and dominant upper limb global strength of institutionalized elderly 
increase with the implementation of a 6-month RNP; H2 - Upper limb flexibility and trunk flexibility of institutionalized elderly increase with the implementation of a 6-month RNP;

H3 - Mobility/global agility and dynamic balance of Of institutionalized elderly increase with the implementation of a 6-month RNP;

H4 - One-leg balance of the dominant lower limb of institutionalized elderly improves with the implementation of a 6-month RNP;

$\mathrm{H} 5$ - Lower limb strength increases of institutionalized elderly with the implementation of a 6-month RNP;

H6 - The values relating to the body composition of of institutionalized elderly change with the implementation of a 6-month RNP.

\section{Methodology}

To achieve the study objectives, an intervention study with a pre-test-post-test design with control group was carried out at the Nursing Home of the Santa Casa de Misericórdia de Bragança, Portugal, for a period of 6 months, from October 2013 to March 2014. The inclusion criteria were as follows: 65 years old or more, able to understand instructions and imitate simple movements, able to walk at least 10 meters (without gait assistance), and able to maintain balance while standing for at least 30 seconds. Older people with unstable medical conditions, who had been hospitalized in the three previous months, and suffered from neuropsychiatric disorders and cognitive impairment (assessed through the Mini-Mental State Examination, setting 24 as the cut-off point) were excluded from the study.

Thus, as according to the flowchart in Figure 1, 30 elderly people met the criteria to participate in the study, five of which were unwilling or unavailable to participate. The remaining 25 participants were randomly assigned through a lottery method to the intervention group $(n=15)$ and the control group $(n=10)$.

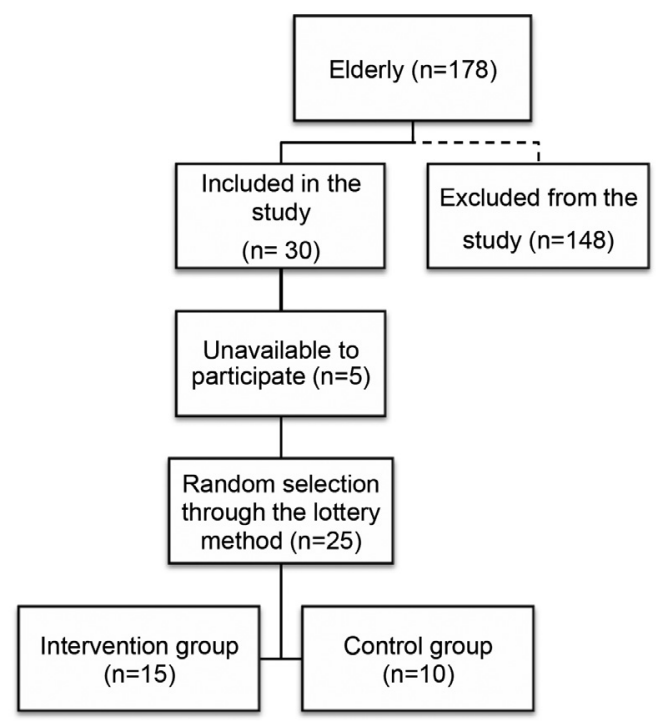

Figure 1. Flowchart of the procedures to form the intervention group.

Sociodemographic data were collected at the beginning of the field work. The variables related to functional fitness were assessed before and after the 6-month RNP. The following variables were assessed: grip strength, pinch strength, upper limb global strength, upper body flexibility, trunk flexibility, mobility/global agility, one-leg balance, lower limb strength, and body composition.
Pinch strength was assessed through the tip-to-tip prehension method between index finger and thumb of the dominant hand, and using a specific digital dynamometer. Grip strength was assessed in the dominant hand, using a universal hydraulic dynamometer and following the protocol recommended by American Society of Hand Therapists (ASHT). The best result of three trials was used. 
Dominant upper limb global strength was assessed through the arm-curl test using a dumbbell, counting the number of repetitions during the timed 30-second interval. Upper body flexibility was assessed through the back-scratch test, which consists in touching both hands together behind the back. Trunk flexibility was assessed through the chair sit-and-reach test, in which the participant sits on a chair and, with both arms extended, tries to reach the toes. Mobility, global agility and dynamic balance were assessed through the up-and-go test, which consists in determining the time required to stand up from a chair, walk 2.44 meters to and around an obstacle, and return to the seated position. Lower limb strength was assessed through the 30-second chair stand, which involves counting the number of times that the participant can fully stand from a chair and return to the seated position within 30 seconds. Static balance was assessed through the one-leg balance test, used to determine the length of time a person can stand on the dominant lower limb with eyes closed.
The tests described above are part of the Functional Fitness Test (FFT) battery designed by Rikli and Jones (1999). This test battery is widely used in clinical practice and research, has consistent reliability and validity, is easily applied, has normative scores per age group, and allows for the comparison of results (Lobo \& Pereira, 2007).

Body composition was analyzed through bioimpedance measurements of body segments, extracting data on weight, muscle mass and bone mass. Height was measured using a regular stadiometer with the purpose of calculating the Body Mass Index (BMI).

The assessments and the intervention were carried out by clinical nurse specialists in rehabilitation nursing, who discussed protocols and standardized procedures prior to field work. Table 1 describes the intervention program, which was carried out three times per week (Mondays, Wednesdays, and Fridays). The RNP design took into account the existing scientific evidence and the components included in similar studies (Crocker et al., 2013; Bastone \& Filho, 2004).

Table 1

RNP components

\begin{tabular}{|c|c|c|c|}
\hline Objectives & & Exercises & Duration $^{1}$ \\
\hline \multicolumn{2}{|c|}{ General warm-up and activation } & Active exercises & $2 '$ \\
\hline & Fingers & Active resistance exercises using springs & $5^{\prime}$ \\
\hline \multirow[t]{2}{*}{ Upper limbs } & Hand & Isometric exercises using balls & 5 \\
\hline & Arm & Active resistance exercises using dumbbells & 5 \\
\hline \multicolumn{2}{|c|}{ Global muscle strength and endurance } & Active and active resistance exercises using a stationary bike. ${ }^{2}$ & 5 \\
\hline \multicolumn{2}{|c|}{ Balance } & $\begin{array}{l}\text { Bend the leg } 15 \text { times, using a chair as support. Walk along a } \\
\text { line. Walk in place. Walk around cones. }\end{array}$ & 5 \\
\hline \multicolumn{2}{|c|}{ Upper and lower limb flexibility. Cool down } & Stretching & $3^{\prime}$ \\
\hline
\end{tabular}

Notes: ${ }^{1}$ Minutes; ${ }^{2}$ Without initial weight, weights were later increased depending on tolerance.

Regarding ethical procedures, we elaborated a study protocol which was submitted to and approved by the Director of the Santa Casa de Misericórdia de Bragança. We explained the study objectives to the participants, who signed the informed consent form. Control group participants were invited to attend a session on health education, focusing on issues related to active aging and healthy lifestyles. As regards data collection and treatment, we followed the classical procedures of descriptive and inferential statistics. The mean scores obtained at the initial and final assessments were compared using the non- -parametric Wilcoxon test. The level of significant of the statistical tests was set at $p<0.05$.

\section{Results}

Table 2 shows the results obtained for the sociodemographic variables in each group. The mean age of both groups was very similar: 85.9 years in the intervention group $(\mathrm{IG})$, and 85.8 years in the control group (CG). Women were predominant in both groups. 
Table 2

Distribution of the participants by sociodemographic variables

\begin{tabular}{lcc}
\hline & $\begin{array}{c}\text { Intervention group } \\
(n=15)\end{array}$ & $\begin{array}{c}\text { Control group } \\
(n=10)\end{array}$ \\
\hline $\begin{array}{l}\text { Age (mean } \pm S D) \\
\text { Gender, } n(\%)\end{array}$ & $85.9 \pm 6.1$ & $85.8 \pm 4.6$ \\
$\quad$ Female & $10(66.7 \%)$ & $7(70.0 \%)$ \\
$\quad$ Male & $5(33.3 \%)$ & $3(30.0 \%)$ \\
Marital status, $n(\%)$ & & \\
$\quad$ Single & $1(6.7 \%)$ & $2(20.0 \%)$ \\
$\quad$ Married/Cohabiting & $0(0.0 \%)$ & $2(20.0 \%)$ \\
$\quad$ Widowed & $14(93.3 \%)$ & $6(60.0 \%)$ \\
\hline
\end{tabular}

Note: $S D=$ Standard Deviation

Table 3 presents the mean scores and standard deviations in the functional fitness variables for the CG and the IG at the beginning and end of the study. In relation to muscle strength, we observed significant gains $(p=0.045)$ in grip strength within the IG. The elderly in the IG improved their dominant upper limb strength, as assessed by the number of arm curls using dumbbells $(p=0.008)$. We also observed increases in lower limb strength in the IG, reflected in the significant increase of the values obtained in the 30-second chair stand $(p=0.003$ ).

With regard to mobility, global agility and dynamic balance, we observed that, at the beginning of the program, the IG participants needed, on average, 17.1 seconds to complete the up-and-go test, and an average of 12.7 seconds to complete it at the end of the intervention $(p=0.003)$. We also observed that the IG improved the one-leg balance $(p=0.004)$.

Table 3

Results obtained in the functional fitness variables before and after the program

\begin{tabular}{|c|c|c|c|c|}
\hline & $\begin{array}{l}\text { Initial assessment } \\
\quad(\text { mean } \pm S D)\end{array}$ & $\begin{array}{l}\text { Final assessment } \\
(\text { mean } \pm S D)\end{array}$ & $\begin{array}{c}\text { Mean } \\
\text { difference }\end{array}$ & $p$ \\
\hline${ }^{1}$ Pinch strengtha $(\mathrm{CG})$ & $4.2 \pm 2.0$ & $3.9 \pm 1.6$ & 0.3 & 0.480 \\
\hline${ }^{1}$ Pinch strengtha ${ }^{\mathrm{a}}(\mathrm{IG})$ & $5.8 \pm 1.7$ & $6.1 \pm 2.2$ & -0.3 & 0.366 \\
\hline${ }^{1}$ Grip strength ${ }^{\mathrm{a}}(\mathrm{CG})$ & $13.7 \pm 8.7$ & $12.7 \pm 9.0$ & 1.0 & 0.380 \\
\hline${ }^{1}$ Grip strength ${ }^{\mathrm{a}}(\mathrm{IG})$ & $15.9 \pm 5.9$ & $18.5 \pm 6.5$ & -2.6 & 0.045 \\
\hline${ }^{2}$ Arm curl with dumbbels ${ }^{b}(\mathrm{CG})$ & $12.0 \pm 4.2$ & $14.7 \pm 6.4$ & -2.7 & 0.072 \\
\hline${ }^{2}$ Arm curl with dumbbels ${ }^{b}$ (IG) & $12.7 \pm 4.6$ & $16.9 \pm 7.5$ & -4.2 & 0.008 \\
\hline${ }^{3}$ Back scratch $(C G)$ & $-27.9 \pm 12.4$ & $-26.8 \pm 10.3$ & -1.1 & 0.372 \\
\hline${ }^{3}$ Back scratch $(\mathrm{IG})$ & $-31.3 \pm 14.7$ & $-25.8 \pm 17.6$ & -5.5 & 0.086 \\
\hline${ }^{3}$ Chair sit-and-reach (CG) & $-13.9 \pm 14.2$ & $-15.5 \pm 15.0$ & 1.6 & 0.343 \\
\hline${ }^{3}$ Chair sit-and-reach (IG) & $-15.5 \pm 16.9$ & $-11.3 \pm 14.4$ & -4.2 & 0.283 \\
\hline${ }^{4}$ Up-and-go $(\mathrm{CG})$ & $20.7 \pm 8.8$ & $21.6 \pm 12.6$ & -0.9 & 0.386 \\
\hline Up-and-go (IG) & $17.1 \pm 6.8$ & $12.7 \pm 4.9$ & 4.4 & 0.003 \\
\hline ²30-second chair stand (CG) & $8.3 \pm 5.0$ & $10.4 \pm 6.3$ & -2.1 & 0.172 \\
\hline ²30-second chair stand (IG) & $9.4 \pm 3.2$ & $12.7 \pm 4.3$ & -3.3 & 0.003 \\
\hline${ }^{4}$ One-leg balancec $(\mathrm{CG})$ & $0.9 \pm 1.3$ & $1.2 \pm 1.8$ & -0.3 & 0.581 \\
\hline${ }^{4}$ One-leg balance $(\mathrm{IG})$ & $1.5 \pm 2.5$ & $2.7 \pm 3.9$ & -1.2 & 0.004 \\
\hline
\end{tabular}

Notes: $p=$ Significance of the non-parametric Wilcoxon test.

${ }^{1}$ Assessed in kilogram-force (Kgf): ${ }^{2}$ Number of repetitions in 30 seconds; ${ }^{3}$ Distance measured in centimeters; ${ }^{4}$ In seconds.

${ }^{a}$ Assessed in the dominant hand; ${ }^{b}$ Assessed in the dominant lower limb; 'Standing on the dominant lower limb.

The Intervention program caused no significant variables (Table 4). changes in weight or in other anthropometric 
Table 4

Anthropometric measurements before and after the program

\begin{tabular}{ccccc}
\hline & $\begin{array}{c}\text { Initial assessment } \\
(\text { mean } \pm S D)\end{array}$ & $\begin{array}{c}\text { Final assessment } \\
(\text { mean } \pm S D)\end{array}$ & Mean difference & $p$ \\
\hline Control Group & & & & 0.1 \\
Weight & $64.6 \pm 7.7$ & $64.5 \pm 7.8$ & 0.0 & 0.499 \\
Height & $1.5 \pm 0.1$ & $1.5 \pm 0.1$ & 0.2 & 0.083 \\
BMI & $27.6 \pm 3.17$ & $27.4 \pm 3.0$ & & 0.260 \\
Intervention Group & & & 0.5 & 0.910 \\
Weight & $71.3 \pm 11.6$ & $70.8 \pm 12.5$ & 0.0 & 0.091 \\
Height & $1.5 \pm 0.1$ & $1.5 \pm 0.1$ & 0.5 & 0.691 \\
BMI & $30.6 \pm 4.1$ & $30.1 \pm 4.1$ & & \\
\hline
\end{tabular}

According to Table 5, either group showed no fat mass percentage, the IG showed a reduction of the significant changes regarding bone mass and muscle fat percentage in the right upper limb $(p=0.041)$ and mass between the initial and final assessments. As for $\operatorname{left}(p=0.035)$.

Table 5

Values of body composition before and after the program

\begin{tabular}{lcccc}
\hline & $\begin{array}{c}\text { Initial assessment } \\
(\text { mean } \pm S D)\end{array}$ & $\begin{array}{c}\text { Final assessment } \\
(\text { mean } \pm S D)\end{array}$ & $\begin{array}{c}\text { Mean } \\
\text { difference }\end{array}$ & $p$ \\
\hline Control Group & & & & \\
\% RUL Fat & $32.2 \pm 9.4$ & $30.5 \pm 7.7$ & 1.7 & 0.214 \\
\% LUL Fat & $29.8 \pm 7.7$ & $28.5 \pm 8.1$ & 1.3 & 0.110 \\
\% RLL Fat & $36.1 \pm 9.1$ & $35.2 \pm 8.4$ & 0.9 & 0.161 \\
\% LLL Fat & $36.7 \pm 9.3$ & $35.7 \pm 8.1$ & 1.0 & 0.214 \\
Bone mass (kg) & $2.2 \pm 0.3$ & $2.2 \pm 0.3$ & 0.0 & 0.058 \\
Total muscle mass (kg) & $38.3 \pm 4.8$ & $39.5 \pm 5.3$ & -1.2 & 0.123 \\
Muscle mass RUL (kg) & $2.1 \pm 0.4$ & $2.1 \pm 0.4$ & 0.0 & 0.096 \\
Muscle mass LUL (kg) & $2.1 \pm 0.3$ & $2.2 \pm 0.4$ & -0.1 & 0.262 \\
Muscle mass RLL (Kg) & $6.5 \pm 1.0$ & $6.8 \pm 1.0$ & -0.3 & 0.091 \\
Muscle mass LLL (Kg) & $6.6 \pm 0.9$ & $6.7 \pm 1.0$ & -0.1 & 0.083 \\
Intervention Group & & & & \\
\% RUL Fat & $35.5 \pm 8.9$ & $33.0 \pm 7.3$ & 2.5 & 0.041 \\
\% LUL Fat & $34.7 \pm 8.8$ & $32.6 \pm 7.6$ & 2.1 & 0.035 \\
\% RLL Fat & $36.1 \pm 11.9$ & $35.5 \pm 10.2$ & 0.6 & 0.629 \\
\% LLL Fat & $36.0 \pm 10.6$ & $34.8 \pm 8.5$ & 1.2 & 0.334 \\
Bone mass (kg) & $2.3 \pm 0.5$ & $2.4 \pm 0.5$ & -0.1 & 0.150 \\
Total muscle mass (kg) & $44.7 \pm 9.3$ & $44.4 \pm 9.3$ & 0.3 & 0.572 \\
Muscle mass RUL (kg) & $2.4 \pm 0.5$ & $2.4 \pm 0.5$ & 0.0 & 0.400 \\
Muscle mass LUL (kg) & $2.4 \pm 0.6$ & $2.3 \pm 0.5$ & 0.1 & 0.926 \\
Muscle mass RLL (Kg) & $7.4 \pm 1.5$ & $7.4 \pm 1.6$ & 0.0 & 0.753 \\
Muscle mass LLL (Kg) & $7.4 \pm 1.7$ & $7.5 \pm 1.4$ & -0.1 & 0.539 \\
\hline
\end{tabular}

Notes: RUL = Right Upper Limb; LUL = Left Upper Limb; RLL = Light Lower Limb; LLL = Left Lower Limb; kg = Kilogram 


\section{Discussion}

The first indicator for the discussion of results is the high age mean of the participants in our study, which was 86 years both in the IG and the CG. In a systematic review conducted by Crocker et al. (2013), the most frequent age mean observed in the studies was 83 years, being that 13 of the 36 reviewed studies included people aged 100 years and over. Thus, age alone is not a contraindication for regular physical activity or participation in appropriate intervention programs using mild-moderate intensity exercises (Crocker et al., 2013; Rydwik et al., 2004).

In accordance with our study objectives, and considering the first research hypothesis, we intended to check whether the RNP increased pinch strength, grip strength, and upper limb global strength. As for pinch strength (which is very important for the daily tasks of older people, such as turning a key, buttoning a shirt or holding a coin), there were no significant changes resulting from the intervention program. Regarding grip strength and arm curl strength, we observed a significant increase at the final assessment. According to Rydwik et al. (2004), there is strong evidence for the benefits of physical training on muscle strength among the elderly. The increase identified in grip and pinch strength and in the dominant upper limb global strength may have translated into an improvement of the functional ability of the elderly in the IG, considering that, according to Vermeulen et al. (2011), these variables are good indicators of functional independence. Souza et al. (2011) believe that muscle strength is the physical ability that is more closely associated with independence.

Upper body flexibility and trunk flexibility, which are relevant variables for the second research hypothesis, presented no significant changes resulting from the RNP, which is in line with other studies (Rydwik et al., 2004). According to Justine, Hamid, Mohan, and Jagannathan (2012), improved flexibility is not as visible as improved muscle strength in most studies. For intervention programs, the authors recommend longer holding times during stretching in order to achieve higher gains in flexibility (Justine et al., 2012). The performance in the up-and-go test improved significantly among the elderly from the IG. Our results are in line with previously published studies (Hanson et al., 2009; Justine et al., 2012). The up-and-go test, by assessing the mobility and agility necessary to gait speed, and the dynamic balance necessary for walking, rounding an obstacle, and returning to the initial position, is a test frequently used to identify individuals at risk of falling. Times higher than $\mathbf{1 3 . 5}$ seconds for completing the test have been considered as an early indicator of frailty and risk of falling among the elderly (Barry, Galvin, Keogh, Horgan, \& Fahey, 2014). Thus, the IG participants, who had completed the test in $17.1 \pm 6.8$ seconds in the initial assessment, completed it in $12.7 \pm 4.9$ seconds at the end of the RNP, i.e. below the recommended cut-off value for risk of falling. We consider that these results point to important health gains for the who participate in the RNP.

One-leg balance while standing on the dominant lower limb showed a statistically significant improvement in the IG. This fact can be explained by a significant increase in the lower limb strength among this group. In fact, lower-limb muscle power, particularly the isometric knee extensors strength plays, together with proprioception and reaction time, an important role in the static balance of the elderly (Bastone \& Filho, 2004; Justine et al., 2012).

In relation to body composition, the results do not confirm $\mathrm{H} 6$ in full and the only relevant change was the reduction of the fat percentage in the left and right upper limbs in the IG participants. This means that the increase in muscle strength, across the different body segments, observed in the IG was not accompanied by an increase in muscle mass. This finding may be explained by the RNP components, described in Table 1 , and the preferred type of exercise (of moderate intensity).

One of the study limitations relates to the difficulty in obtaining a more representative sample, which is partially explained by the high number of older people excluded from the study due to balance deficits and/ or gait changes. Additionally, this research did not focus on the impact of the program on some relevant psychosocial variables, such as mood and health-related quality of life.

\section{Conclusion}

Most of the studies available on the effectiveness of intervention programs using physical exercise to increase strength, balance and flexibility are community-based, and show some limitations 
when applied to institutionalized elderly (Justine et al., 2012). Our study can, therefore, contribute to extending the knowledge on the researched issue. The results from this study may be integrated into clinical practice, or serve as a starting point for further studies.

The implemented RNP included all components of the functional fitness of the elderly: strength, aerobic training, flexibility, balance, and body composition. These components were assessed with widely used instruments, and the intervention was carried out using cost-effective equipment and following the protocols applied in several studies. Although these results should be carefully interpreted, they suggest that an intervention program using moderateintensity physical activity, in three weekly 30-minute sessions, for a period of 6 months, can improve the functional fitness and reduce the risk of falling among institutionalized elderly.

\section{References}

Barry, E., Galvin, R., Keogh, C., Horgan, F., \& Fahey, T. (2014). Is the Timed Up and Go test a useful predictor of risk of falls in community dwelling older adults: A systematic review and meta-analysis. BMC Geriatrics, 14,14. doi:10.1186/1471-2318$14-14$

Bastone, A., \& Filho, W. (2004). Effect of an exercise program on functional performance of institutionalized elderly. Journal of Rebabilitation Research Development, 41(5), 659-668. doi: 10.1682/JRRD.2O03.01.0014

Carneiro, R., Soares, C., Fialho, J., \& Sacadura, M. (2012). O envelhecimento da população: Dependência, ativação e qualidade (Relatório final). Universidade Católica Portuguesa, Faculdade de Ciências Humanas, Centro de Estudos dos Povos e Culturas de Expressão Portuguesa, Lisboa, Portugal. Retrieved from http://www.qren.pt/np4/np 4/?newsId $=1334 \&$ fileName $=$ envelhecimento_populacao. pdf

Caspersen, C. J., Powell, K. E., \& Christenson, G. M. (1985). Physical activity, exercise, and physical fitness: Definitions and distinctions for health-related research. Public Health Reports, 100(2), 126-131. Retrieved frome http://www.ncbi. nlm.nih.gov/pmc/articles/PMC1424733/

Chávez-Pantoja, M., López-Mendoza, M., \& Mayta-Tristán, P. (2014). Efecto de un programa de ejercicios fisioterapéuticos sobre el desempeño físico en adultos mayores institucionalizados. Revista Espanbola de Geriatria e Gerontologia, 49(6), 260265. doi: 10.1016/j.regg.2014.05.010

Chou, C. H., Hwang, C. L., \& Wu, Y. T. (2012). Effect of exercise on physical function, daily living activities, and quality of life in the frail older adults: A meta-analysis. Archives of Physical Medicine and Rebabilitation, 93(2), 237-244. doi: 10.1016/j. apmr.2011.08.042

Crocker, T., Forster, A., Young, J., Brown, L., Ozer, S., Smith, J., ... Greenwood, D. C. (2013). Physical rehabilitation for older people in long-term care. The Cochrane Database of Systematic Reviews, 2, CD004294. doi: 10.1002/14651858. CD004294.pub3

El-Khoury, F., Cassou, B., Charles, M. A., \& Dargent-Molina, P. (2013). The effect of fall prevention exercise programmes on fall induced injuries in community dwelling older adults: Systematic review and meta-analysis of randomised controlled trials. British Medical Journal, 347, f6234. doi: $10.1136 /$ bmj.f6234

Elbaz, A., Vicente-Vytopilova, P., Tavernier, B., Sabia, S., Dumurgier, J., Mazoyer, B., ... Tzourio, C. (2013). Motor function in the elderly: Evidence for the reserve hypothesis. Neurology, 81(5), 417-426. doi: 10.1212/WNL.0b013e31829d8761

Hanson, E. D., Srivatsan, S. R., Agrawal, S., Menon, K. S., Delmonico, M. J., Wang, M. Q., \& Hurley, B. F. (2009). Effects of strength training on physical function: Influence of power, strength, and body composition. The Journal of Strength E Conditioning Research, 23(9), 2627-2637. doi: 10.1519/ JSC.0b013e3181b2297b

Justine, M., Hamid, T., Mohan, V., \& Jagannathan, M. (2012). Effects of multicomponent exercise training on physical functioning among institutionalized elderly. International Scholarly Research Network Rebabilitation, 2012. Retrieved from http://www.hindawi.com/journals/isrn/2012/124916/

Lobo, A., \& Pereira, A. (2007). Idoso institucionalizado: Funcionalidade e aptidão física. Revista de Enfermagem Referência, 2(4), 61-68. Recuperado de http://www.index-f. com/referencia/2007pdf/61-2007-jun.pdf

Preto, L., Santos, A. L., Mendes, M. E., Novo, A. P., \& Pimentel, M. H. (2015). Deterioro funcional, miedo a caerse y composición corporal en ancianos institucionalizados. Enfermeria Clinica,25(2), 81-86. doi: 10.1016/j.enfcli.2014.10.005

Rikli, R., \& Jones, J. (1999). Development and validation of a functional fitness test for community-residing older adults. Journal of Aging and Physical Activity, 7, 129-161. Retrieved from http://www.luzimarteixeira.com.br/wpcontent/uploads/2010/10/functinal-fitness.pdf

Rikli, R., \& Jones, J. (2008). Teste de aptidão física para idosos. São Paulo, Brasil: Manole.

Rondanelli, M., Guido, D., Opizzi, A., Faliva, M. A., Perna, S., \& Grassi, M. (2014). A path model of sarcopenia on bone mass loss in elderly subjects. The Journal of Nutrition Health $\mathcal{E}$ Aging, 18(1), 15-21. doi: 10.1007/s12603-013-0357-4

Rydwik, E., Frändin, K., \& Akner, G. (2004). Effects of physical training on physical performance in institutionalised elderly patients $(70+)$ with multiple diagnoses. Age Ageing, 33(1), 13-23. doi: 10.1093/ageing/afh001

Souza, P., Benedetti, T., Borges, L., Mazo, G., \& Gonçalves, L. 
(2011). Aptidão funcional de idosos residentes em uma instituição de longa permanência. Revista Brasileira Geriatria Gerontologia, 14(1), 07-16. Retrieved from http:// www.scielo.br/pdf/rbgg/v14n1/a02v14n1.pdf

Vermeulen, J., Neyens, J. C., Rossum, E., Spreeuwenberg, M. D., \& Witte, L. P. (2011). Predicting ADL disability in communitydwelling elderly people using physical frailty indicators: a systematic review. BMC Geriatrics, 11, 33. doi: 10.1186/14712318-11-33

Vieira, D. C., Tibana, R. A., Tajra, V., Nascimento, D., Farias, D. L., Silva, A. O., ... Prestes, J. (2013). Decreased functional capacity and muscle strength in elderly women with metabolic syndrome. Clinical Interventions in Aging, 8, 1377-1386. doi: 10.2147/CIA.S50333 
